\title{
ASSESSMENT OF THE QUALITY OF LIFE AND PERFORMANCE STATUS IN PATIENTS WITH ORAL SUBMUCOUS FIBROSIS IN CENTRAL INDIA
}

\author{
REVANT H. CHOLE ${ }^{1}$, RANJITKUMAR PATIL ${ }^{2}$
}

\author{
${ }^{1}$ Oral Medicine and Radiology Department, Dr. H.S.R.S. Mandal's Dental College \\ and Hospital, Hingoli, Maharashtra, India \\ ${ }^{2}$ Oral Medicine and Radiology Department, KGMC Lucknow, India
}

\begin{abstract}
Background and aims. Measuring quality of life in patients with oral submucous fibrosis is of utmost importance in assessing treatment outcomes. This study examined the impact of oral submucous fibrosis and its treatment on the quality of life and performance status of persons with oral submucous fibrosis.

Methods. Quality of life was measured in patients with oral submucous fibrosis using the European Organization for Research and Treatment of Cancer Quality of Life head and neck 35 Questionnaire (EORTC QLQ-C35); performance status was measured by Performance Status Scale for Head and Neck Cancer Patients (PSS-HN), at four points in time: baseline, one month, two months and three months after start of treatment.

Results. At the end of third month Group A and Group B showed $78 \%$ and $85 \%$ increase in mouth opening respectively. While the burning sensation of oral mucosa was decreased by $72 \%$ and $88 \%$ in group $A$ and group B respectively $(Z>1.96$, $P<0.05)$, there were significant differences in patients' quality of life and functioning at three points in time $(P<0.05)$.

Conclusion. The European Organization for Research and Treatment of Cancer Quality of Life head and neck 35 Questionnaire and Performance Status Scale for Head and Neck Cancer Patients can be used successfully in potentially malignant disorders like oral submucous fibrosis. The results in this study will surely be a good guide forother studies on oral submucous fibrosis.
\end{abstract}

Keywords: oral submucous fibrosis, quality of life, EORTC, performance status

\section{Introduction}

Oral submucous fibrosis (OSMF) is a potentially malignant condition of the oral cavity characterized by juxta-epithelial inflammatory reaction and progressive fibrosis of the lamina propria and deeper connective tissues of the upper digestive tract involving the oral cavity, oropharynx and frequently the upper third of the oesophagus. Measuring quality of life (QOL) in OSMF

Manuscript received: 28.04.2017

Received in revised form: 01.06.2017

Accepted: 20.06.2017

Address for correspondence: drchole@rediffmail.com has not been the focus of clinical practice and research in the past decades; however it is of importance in assessing treatment outcomes. This is partly due to the increasing number of OSMF and oral cancer patients. Also, OSMF affects a person's identity and therefore studying the quality of life in such persons is important. QOL is both clinically and physiologically a meaningful endpoint and is best defined from the patient's perspective [1]. The World Health Organization (WHO) defines QOL as an individual's perception of his or her position in life in the context of the culture and value systems in which the patient lives and in relation to his or her goals, expectations, standards and 
concerns [2]. The importance of QOL has been increasingly recognized and is reflected in its use as an outcome measure in cancer research, at par with response rate and survival [3]. OSMF can cause profound effects on the quality of life of a patient for many years even after treatment. Many factors, such as reduced mouth opening, oral ulcers, burning sensation in oral mucosa, could influence the overall QOL in patients with OSMF.

Therefore, this study was undertaken to evaluate the effect of OSMF on patient's quality of life and performance status and to assess one to three months effects of disease and treatment on patient's QOL and performance status.

\section{Materials and methods Design}

This was a prospective study of quality of life in OSMF patients. The study was conducted in Bhabha College of Dental Sciences, Bhopal, India, during one complete calendar year from April 2015 to March 2016. Bhabha College of Dental Sciences is one of the reputed dental teaching hospitals in Central India, affiliated to Madhya Pradesh University of Health Sciences. We identified 100 OSMF patients attending the dental outpatient department (OPD) who were interviewed at this baseline stage. A detailed case history of all patients was recorded and diagnosis of OSMF was made by clinical examination. The one hundred oral submucous fibrosis patients were divided into two groups, Group A and Group B. Group A $(\mathrm{n}=50)$ received oral Spirulina capsule $500 \mathrm{mg}$ twice daily. Group B $(\mathrm{n}=50)$ received oral Spirulina capsule $500 \mathrm{mg}$ twice daily along with topical triamcinolone acetonide $0.1 \%$. There were no restrictions on patient selection with regard to history of areca nut use, disease stage and demographic characteristics. First follow-up was scheduled one month after initial treatment and the subsequent assessments were made two and three months after initial treatment. The ethical committee of the institute approved the study and treatment was carried out with the patients' permissions.

\section{Measures}

Quality of life was measured using the European Organization for Research and Treatment of Cancer Quality of Life head and neck 35 Questionnaire (EORTC QLQ-C35). The head \& neck cancer module is meant for use among a wide range of patients with head \& neck cancer, varying in disease stage and treatment modality [4,5]. The EORTC QLQ-C35 is a well-known instrument for measuring quality of life in head and neck cancer patients and contains 35 items that measure symptoms and side effects of treatment, social function and body image/sexuality. Seven multi-item scales are incorporated in the head \& neck cancer module that assess pain, swallowing, senses (taste and smell), speech, social eating, social contact and sexuality. Other than this there are eleven single items.

The second scale used in this research was the Performance Status Scale for Head and Neck Cancer Patients (PSS-HN). It consists of three subscales: Normalcy of Diet, Understandability of Speech, and Eating in Public. Scores on each subscale range from 0 to 100 , with higher scores indicating better performance [6]. The questionnaires were administered at four points in time: baseline, one month, second month and three months after commencement of treatment.

\section{Results}

In this study we had 100 patients with ages between 14 and 47 years. Most of the patients were men (94\%), coming from central India region, low income, exposed to at least one risk factor, almost all were betel nut chewers, while $34 \%$ were both chewers and smokers. OSMF lesions was more frequently located on the buccal mucosa $(83 \%)$, followed by retromolar region (46\%), labial mucosa $(21 \%)$ and palate $(17 \%)$. At the end of third month Group A and Group B showed 78\% and $85 \%$ increase in mouth opening respectively. Burning sensation of oral mucosa was decreased by $72 \%$ and $88 \%$ in group A and group B respectively $(\mathrm{Z}>1.96, \mathrm{P}<0.05)$ (Table I).

The QLQ-H\&N35 questionnaire was applied before starting the treatment, and subsequently at 1,2 and 3 months later. After one, two and three month of treatment, compared to before starting the treatment, all symptom scales of the quality of life were affected negatively. At the end of 3rd month after the treatment, there was a decrease in the pain, in swallowing problems, in speech problems, in problems with eating in a social environment, in problems with socializing with other people, in feeling sick, in loss of sexual desire and in opening mouth. Compared with Group A, Group B had better outcome in mouth opening, burning sensation, pain, swallowing, senses (taste/smell), speech, social eating, social contact, teeth, dry mouth, sticky saliva, and feeling ill, but with statistically significant difference in pain, senses (taste/smell), speech, social eating, social contact, teeth and opening mouth (Table II).

Functional measures related to eating improved over time with normalcy of diet, public eating, and understandability of speech, all increasing within 1,2 and 3 months post treatment. Linear regression coefficients were calculated for each measure across the 60 subjects. All the functional measures of eating (PSSD, PSSE and PSSS) demonstrated significant linear increase over time, indicating an improvement in function (Table III). PSSD had a mean regression coefficient of $4.55(p<0.005)$, PSSE had a mean regression coefficient of $2.74(p<0.005)$, and PSSS had a mean regression coefficient of $5.27(p<0.005)$. 
Table I. Mode of management of oral submucous fibrosis.

\begin{tabular}{|l|l|l|l|l|}
\hline Mode of management & \multirow{2}{*}{ No. of patients } & \multicolumn{2}{|c|}{ Relief of symptoms/signs } & \\
\cline { 3 - 5 } & & Mouth opening & Burning sensation & \\
\hline Spirulina 500 mg BD & 50 & $78 \%$ & $72 \%$ & $Z>1.96$ \\
\hline Spirulina + Triamcinolone acetonide $0.1 \%$ & 50 & $85 \%$ & $88 \%$ & $\mathrm{P}<0.05$ \\
\hline
\end{tabular}

Table II. EORTC QLQ-H\&N35 - A comparison of the OSMF patients before and after treatment.

\begin{tabular}{|c|c|c|c|c|}
\hline & & Group A & Group B & p Value \\
\hline & & Mean (SD) & Mean (SD) & Mean (SD) \\
\hline \multirow[t]{35}{*}{ Symptom scale } & Pain & V & & \\
\hline & Baseline & $25.1(22.7)$ & $23.8(15.4)$ & NS \\
\hline & 1 Month & $21.5(15.9)$ & $19.3(17.7)$ & NS \\
\hline & 2 Months & $18.6(24.7)$ & $15.5(10.2)$ & $\mathrm{p}<0.05$ \\
\hline & 3 Months & $14.3(18.7)$ & $10.2(15.8)$ & $\mathrm{p}<0.05$ \\
\hline & Swallowing & & & \\
\hline & Baseline & $18.7(14.2)$ & $20.1(11.0)$ & NS \\
\hline & 1 Month & $19.2(17.3)$ & $18.5(16.1)$ & NS \\
\hline & 2 Months & $17.5(11.7)$ & $18.1(22.2)$ & NS \\
\hline & 3 Months & $16.2(22.7)$ & $14.9(18.5)$ & NS \\
\hline & Senses (Taste/Smell) & & & \\
\hline & Baseline & $24.7(15.4)$ & $28.6(21.2)$ & NS \\
\hline & 1 Month & $24.4(16.4)$ & $23.5(13.1)$ & NS \\
\hline & 2 Months & $23.2(13.8)$ & $19.3(10.5)$ & $\mathrm{p}<0.05$ \\
\hline & 3 Months & $20.6(17.8)$ & $17.5(21.3)$ & NS \\
\hline & Speech & & & \\
\hline & Baseline & $25.5(23.7)$ & $25.1(21.5)$ & NS \\
\hline & 1 Month & $24.3(17.1)$ & $19.4(11.7)$ & $\mathrm{p}<0.05$ \\
\hline & 2 Months & $21.4(13.5)$ & $18.2(19.1)$ & NS \\
\hline & 3 Months & $20.1(14.5)$ & $18.1(10.7)$ & NS \\
\hline & Social eating & & & \\
\hline & Baseline & $18.6(14.5)$ & $22.8(14.5)$ & $\mathrm{p}<0.05$ \\
\hline & 1 Month & $18.2(12.6)$ & $21.4(13.8)$ & NS \\
\hline & 2 Months & 17.7 (15.6) & $18.5(12.8)$ & NS \\
\hline & 3 Months & $17.2(21.1)$ & $17.0(11.8)$ & NS \\
\hline & Social contact & & & \\
\hline & Baseline & $22.5(13.6)$ & $21.4(13.4)$ & NS \\
\hline & 1 Month & $21.7(14.2)$ & $16.3(10.2)$ & $\mathrm{p}<0.05$ \\
\hline & 2 Months & $20.6(14.7)$ & $15.7(16.9)$ & $\mathrm{p}<0.05$ \\
\hline & 3 Months & 17.5 (15.4) & $15.9(10.8)$ & NS \\
\hline & Sexuality & & & \\
\hline & Baseline & $15.1(14.7)$ & $16.4(11.3)$ & NS \\
\hline & 1 Month & $16.6(13.7)$ & $17.8(12.1)$ & NS \\
\hline & 2 Months & $15.2(10.3)$ & $15.8(11.8)$ & NS \\
\hline & 3 Months & $15.1(11.4)$ & $14.9(10.4)$ & NS \\
\hline
\end{tabular}




\begin{tabular}{|c|c|c|c|c|}
\hline & & Group A & Group B & p Value \\
\hline & & Mean (SD) & Mean (SD) & Mean (SD) \\
\hline \multirow[t]{30}{*}{ Single item } & Problems with teeth & v & & \\
\hline & Baseline & $24.3(18.3)$ & $23.1(18.2)$ & NS \\
\hline & 1 Month & $22.5(13.2)$ & $22.3(12.3)$ & NS \\
\hline & 2 Months & $22.8(13.5)$ & $20.7(15.8)$ & NS \\
\hline & 3 Months & $20.4(10.3)$ & $19.8(14.2)$ & NS \\
\hline & Opening mouth & & & \\
\hline & Baseline & $37.5(15.7)$ & $37.2(14.5)$ & NS \\
\hline & 1 Month & $42.5(16.4)$ & $43.0(10.3)$ & NS \\
\hline & 2 Months & $40.8(11.5)$ & $45.7(14.1)$ & $\mathrm{p}<0.05$ \\
\hline & 3 Months & $42.9(17.3)$ & $49.2(11.2)$ & $\mathrm{p}<0.05$ \\
\hline & Dry mouth & & & \\
\hline & Baseline & $23.6(14.4)$ & $24.1(16.7)$ & NS \\
\hline & 1 Month & $21.2(11.5)$ & $22.4(12.2)$ & NS \\
\hline & 2 Months & $18.2(14.4)$ & $18.9(16.8)$ & NS \\
\hline & 3 Months & $17.5(11.7)$ & $16.3(13.5)$ & NS \\
\hline & Sticky saliva & & & \\
\hline & Baseline & $14.6(10.7)$ & $15.3(12.2)$ & NS \\
\hline & 1 Month & $14.1(16.2)$ & $14.9(12.5)$ & NS \\
\hline & 2 Months & $12.1(12.0)$ & $12.7(10.7)$ & NS \\
\hline & 3 Months & $10.2(10.5)$ & $10.3(12.2)$ & NS \\
\hline & Coughing & & & \\
\hline & Baseline & $9.4(7.5)$ & $11.4(8.3)$ & NS \\
\hline & 1 Month & $9.2(6.5)$ & $9.8(12.5)$ & NS \\
\hline & 2 Months & $8.2(7.2)$ & $8.1(6.4)$ & NS \\
\hline & 3 Months & $8.8(9.2)$ & $8.0(6.3)$ & NS \\
\hline & Feeling ill & & & \\
\hline & Baseline & $18.3(13.7)$ & $15.9(11.2)$ & NS \\
\hline & 1 Month & $17.4(13.6)$ & $14.5(12.8)$ & NS \\
\hline & 2 Months & $17.0(8.2)$ & \begin{tabular}{|l|}
$13.3(7.1)$ \\
\end{tabular} & NS \\
\hline & 3 Months & $15.8(6.4)$ & $11.2(6.5)$ & NS \\
\hline
\end{tabular}

NS = Not significant

Table III. Performance status scale in oral submucous fibrosis.

\begin{tabular}{|l|l|l|l|}
\hline & & Group A & Group B \\
\hline PSSD (p<0.05) & Baseline & $40.7(11.5)$ & $37.2(12.6)$ \\
\hline & 1 Month & $42.4(12.2)$ & $45.6(25.8)$ \\
\hline & 2 Months & $48.4(20.3)$ & $58.1(28.2)$ \\
\hline & 3 Months & $60.4(10.4)$ & $71.3(32.5)$ \\
\hline PSSE (p<0.05) & Baseline & $38.3(13.6)$ & $41.5(13.7)$ \\
\hline & 1 Month & $40.5(10.2)$ & $44.5(26.4)$ \\
\hline & 2 Months & $55.1(24.0)$ & $65.1(33.7)$ \\
\hline & 3 Months & $67.6(15.8)$ & $71.2(36.2)$ \\
\hline PSSS (p<0.05) & Baseline & $48.2(11.4)$ & $46.1(22.9)$ \\
\hline & 1 Month & $50.7(16.1)$ & $52.1(24.9)$ \\
\hline & 2 Months & $57.3(22.5)$ & $65.7(18.5)$ \\
\hline & 3 Months & $70.7(16.1)$ & $78.6(21.7)$ \\
\hline
\end{tabular}




\section{Discussion}

There is limited robust evidence to conclusively derive the impact of OSMF on quality of life. Health-related quality of life (HR-QOL) and its assessment have become increasingly important in health care. HR-QOL generally refers to the patient's perception of the effects of the disease and the impact on the patient's daily functioning. This study has a number of important strengths. Not only did we measure quality of life outcomes at one, two and three months after OSMF diagnosis, we also measured quality of life at baseline and had control data for comparison. QOL is an important outcome to be considered in clinical trials and in routine treatment. Its assessment can be challenging at times; however, there are reliable and valid tools available and clinicians can use them meaningfully if they know how to apply them and how to interpret their scores.

The past four decades have seen the development of a new technology in medicine and dentistry that is based entirely on data obtained from patients' self-reports of their symptoms and functional status. In our study the treatment continued for a period of three months and the QLQ-H\&N35 questionnaire was applied before starting the treatment, and subsequently at 1,2 and 3 months later. All symptom scales of the quality of life were affected negatively during the treatment. At the end of the third month, there was a decrease in the pain, improvement in swallowing, speech, eating in a social environment, socializing with other people and increase in opening mouth. Compared with Group A, Group B had better outcome in mouth opening, pain, burning sensation, swallowing, senses (taste/smell), speech, social contact, social eating, dry mouth, teeth, sticky saliva, and feeling ill, but with statistically significant difference in pain, senses, speech, social contact, social eating, teeth and opening mouth (Table II). A study in head and neck cancer patients, showed that there was a significant reduction in the quality of life for some common symptoms resulting from cancer treatment, which was not seen in the evaluation of the aspects related to physical, cognitive and social functions, and general health [7]. Another study stated that the QLQ$\mathrm{H} \& \mathrm{~N} 35$, in conjunction with the QLQ-C30, provides a valuable tool for the assessment of health-related quality of life in clinical studies of H\&N cancer patients before, during, and after treatment with radiotherapy, surgery, or chemotherapy [5].

In our study, burning sensation in oral mucosa was present in the first month of the assessment, and declined in the subsequent months. A study on parotid tumors reported that EORTC QLQ-C30 questionnaire parameters on social functioning and financial difficulties, and EORTC QLQH\&N35 questionnaire parameters on speech problems, reduced sexuality, and nutritional support revealed statistically meaningful results $(p<0.001)$ [8]. Another study in India has suggested that the EORTC QLO-C30 and the QLQ-H\&N 35 are reliable and valid questionnaires when applied to a sample of head and neck cancer patients in India [9]. A study in Nepal showed that the Nepalese version of Oral Health Impact Profile-14 is a valid and reliable instrument to measure oral health related quality of life in OSMF patients, and QOL in OSMF patients can be improved after professional treatment regime [10]. A study from India used General Health Questionnaire-28 to assess the psychological morbidity in OSMF, and stated that OSMF may be associated with considerable psychological morbidity and but it is difficult to determine whether this is the cause or effect of the disease [11]. Another study suggested the association of substantial psychiatric morbidity among patients with OSMF, and advised their psychiatric management [12]. A study on oral precancer showed that patients with oral precancer had the highest HR-QOL, as compared to oral cancer. They also stated anxiety to be of key importance for the oral precancer group, whereas appearance and activity are of importance for the patients having oral cancer [13]. Further one study showed poorer QOL and higher depression scores in oral cancer, whereas their results showed better scores for patients with oral lichen planus in the social support and spirituality categories, as compared to oral cancer group [14].

Performance status scale showed improved eating over time with normalcy of diet, public eating, and understandability of speech, all increasing between 1, 2 and 3 months post treatment. There was significant linear increases over time with functional measures of eating (PSSD, PSSE and PSSS), indicating an improvement in function. PSSD had a mean regression coefficient of 4.52 $(p<0.005)$, PSSE had a mean regression coefficient of 2.76 $(p<0.005)$, and PSSS had a mean regression coefficient of $5.28(\mathrm{p}<0.005)$. One study showed that the pattern of correlations between FACT-H\&N and PSS-HN subscales supported the scales' construct validity. PSS-HN Normalcy of Diet and Eating in Public, and the head and neck subscale (HNS) of FACT-H\&N, showed most significant associations. The PSS-HN provides unique information, independent of that provided by the Karnofsky or the FACT-H\&N [8].

\section{Conclusion}

Assessing the quality of life of OSMF patients is complex, considering the large number of variables which impact the patient's self-perception; still it was a sincere attempt to assess quality of life and performance status in OSMF. In future, the results of our study will surely be a good guide to outcomes from other studies on OSMF. We would like to further state that the European Organization for Research and Treatment of Cancer Quality of Life head and neck 35 Questionnaire (EORTC QLQ-C35) and Performance Status Scale for Head and Neck Cancer Patients (PSS-HN) can be used successfully in potentially 
malignant disorder like oral submucous fibrosis.

\section{References}

1. Gill TM, Feinstein AR. A critical appraisal of the quality of quality-of-life measurements. JAMA. 1994;272(8):619-626.

2. WHOQOL. Measuring quality of life. Programme on Mental Health, 1997 Available from: http://www.who.int/mental health/ media/68.pdf

3. Heutte N, Plisson L, Lange M, Prevost V, Babin E. Quality of life tools in head and neck oncology. Eur Ann Otorhinolaryngol Head Neck Dis. 2014;131:33-47.

4. Bjordal K, Ahlner-Elmqvist M, Tollesson E, Jensen AB, Razavi $\mathrm{D}$, Maher EJ, et al. Development of a European Organization for Research and Treatment of Cancer (EORTC) questionnaire module to be used in quality of life assessments in head and neck cancer. EORTC Quality of Life Study Group. Acta Oncol. 1994;33(8):879-885.

5. Bjordal K, Hammerlid E, Ahlner-Elmqvist M, de Graeff A, Boysen M, Evensen JF, et al. Quality of life in head and neck cancer patients: validation of the European Organization for Research and Treatment of Cancer Quality of Life QuestionnaireH\&N35. J Clin Oncol. 1999;17(3):1008-1019.

6. List MA, D'Antonio LL, Cella DF, Siston A, Mumby P, Haraf D, et al. The Performance Status Scale for Head and Neck Cancer Patients and the Functional Assessment of Cancer TherapyHead and Neck Scale: A study of utility and validity. Cancer. 1996;77(11):2294-2301.

7. Melo Filho MR, Rocha BA, Pires MB, Fonseca ES, Freitas EM, Martelli Junior H, et al. Quality of life of patients with head and neck cancer. Braz J Otorhinolaryngol. 2013;79:82-88.

8. Gunsoy B, Vuralkan E, Sonbay ND, Simsek G, Tokgoz SA, Akin I. Quality of life following surgical treatment of benign parotid disease. Indian J Otolaryngol Head Neck Surg. 2013;65(Suppl 1):105-111.

9. Chaukar DA, Das AK, Deshpande MS, Pai PS, Pathak KA, Chaturvedi P, et al. Quality of life of head and neck cancer patients: validation of the European organization for research and treatment of cancer QLQ-C30 and European organization for research and treatment of cancer QLQ-H\&N C35 in Indian patients. Indian J Cancer. 2005;42(4):178-184.

10. Rimal J, Shrestha A. Validation of Nepalese Oral Health Impact Profile14 and Assessment of Its Impact in Patients with Oral Submucous Fibrosis in Nepal. J Nepal Health Res Counc. 2015;13(29):43-49.

11. Mubeen K, Kumar CN, Puja R, Jigna VR, Chandrashekar H. Psychiatric morbidity among patients with oral sub-mucous fibrosis: a preliminary study. J Oral Pathol Med. 2010;39(10):761764.

12. Raja JV, Rai P, Kumar NC, Khan M, Chandrashekar H. Psychiatric morbidity among patients with oral submucous fibrosis: a controlled study. Oral Health Dent Manag. 2013;12(2):85-94.

13. Rana M, Gellrich NC, Rana M. Comparison of health-related quality of life of patients with different precancer and oral cancer stages. Clin Oral Investig. 2015;19(2):481-488.

14. Rana M, Kanatas A, Herzberg PY, Gellrich NC, Rana M. Relevance of psychosocial factors to quality of life in oral cancer and oral lichen planus: a prospective comparative study. Br J Oral Maxillofac Surg. 2015;53(7):621-626. 